\title{
A Model-Based Approach of DC-DC Converters Dedicated to Controller Design Applications for Photovoltaic Generators
}

\author{
Zeineb Rania Labidi \\ Laboratory of Application of Energy, \\ Efficiency and Renewable Energies, \\ Faculty of Sciences of Tunis, Tunis El \\ Manar University, Tunis, Tunisia \\ zeinebrania.labidi@fst.utm.tn
}

\author{
Horst Schulte \\ Department of Engineering, \\ University of Applied Sciences for \\ Engineering and Economics, \\ Berlin, Germany \\ horst.schulte@htw-berlin.de
}

\author{
Abdelkader Mami \\ Laboratory of Application of Energy, \\ Efficiency and Renewable Energies, \\ Faculty of Sciences of Tunis, Tunis El \\ Manar University, Tunis, Tunisia \\ abdelkader.mami@fst.utm.tn
}

\begin{abstract}
In this paper, a model-based approach of DC-DC converters dedicated to controller design applications for photovoltaic generators is introduced. The paper provides a mathematic averaging model, based on the state space method for DC-DC converters that is used as an adaptation level in photovoltaic generators. This modeling allows the dynamics of the system to be described by presenting a reliable model to be used for oriented controller design. The two most needed topologies of DC-DC converters are proposed, buck and buckboost, and an overview of integral state feedback controller design using a model-based approach for a boost converter connected to a photovoltaic generator described in our previous published work is provided. The model-based conception of both converter types is analyzed for optimal use in control-oriented design. The validation of each model is demonstrated by comparative curves represented by a detailed plant model using Simscape devices available and implemented in Simulink/Matlab
\end{abstract}

Keywords-model-based approach; buck converter; buck-boost converter; state-space modeling; photovoltaic generator

\section{INTRODUCTION}

Recently, worldwide focus has been directed to the research of water management systems for agricultural and food production [1]. In providing these systems, especially to rural near-desert areas, the most optimal solution is the use of offgrid renewable energy generators [2, 3]. Voltage adjustment between these generators (as photovoltaic (PV) arrays) and load requires the adoption of direct current-direct current (DCDC) converters, which enable the maximum extraction of power available through appropriate control techniques. These converters also regulate the output DC voltage that is needed as a DC bus connection for hybrid systems of renewable energy. The use of DC-DC converters, in turn, necessitates the implementation of a model-based approach to controller design. In this regard, interest lies in the DC-DC converters employed in PV generator applications. In [4], the authors compared different topologies on the basis of varying applications and comprehensively discussed the advantages and disadvantages of each topology in terms of costs, components, efficiency, and limitations. They indicated that a buck converter is optimal for standalone solar PV pumping systems intended to supply water to rural areas, that a boost converter exhibits good dynamic performance in load balancing, and that a buck-boost converter is the most efficient tool for drawing maximum power from PV panels, regardless of load conditions. In our previous work [5], integral statefeedback control was designed using a model-based approach to ensure control in a boost converter connected to a PV array, which was modeled as a current source. The present study aims at modeling two topologies (buck and buck-boost converter), necessary in the design of different control mechanisms, such as integral feedback control, model predictive control, and observer-based control. To this end, we used an analytical model-based approach that is relevant to practical applications.

\section{OVERVIEW OF MODEL-BASED APPROACH FOR BOOST CONVERTER}

This section summarizes the most important steps in building an oriented controller through the proposed modelbased approach of a boost converter [5]. It also recounts the analysis of the oriented model for application purposes. We note that a detailed explanation of the PV generator is presented in [5], hence it will be applied directly in this work.

\section{A. Model-based Approach}

The particularity of the model-based approach of the boost converter connected through a PV array is that the input of the converter is not a simple voltage constant [6], but the equivalent circuit of the PV array as a current source (Figure 1). This way, the system matrix describes the exact dynamic interaction between source (PV panels) and load. In the system, solar radiation is defined as a non-controllable input, whereas the duty cycle represents controllable input.

$$
\left[\begin{array}{c}
\frac{d V_{P V}}{d t} \\
\frac{d i}{d t} \\
\frac{d V_{D C}}{d t}
\end{array}\right]=A\left[\begin{array}{c}
V_{p v} \\
i \\
V_{D C}
\end{array}\right]+B u(t)+D
$$


To extract the average matrix of the system (2) and use it for the oriented controller [5], we first defined the system's state variables, namely, the voltage and current flowing through inductors and capacitances. We then converted the differential equations for on and off modes into the form presented in (1).

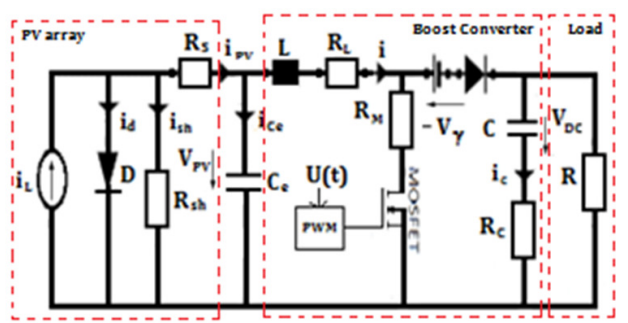

Fig. 1. Equivalent electrical circuit of the system with a boost converter

$$
\begin{aligned}
& {\left[\begin{array}{c}
\frac{d V_{P V}}{d t} \\
\frac{d i}{d t} \\
\frac{d V_{D C}}{d t}
\end{array}\right]=\left[\begin{array}{ccc}
-\frac{1}{C_{e}\left(R_{S h}+R_{S}\right)} & -\frac{1}{C_{e}} & 0 \\
\frac{1}{L} & -\left(\frac{R R_{c}+R_{L} R_{C}+R R_{L}}{L\left(R_{c}+R\right)}\right) & -\frac{R}{L\left(R_{c}+R\right)} \\
0 & \frac{R}{C\left(R+R_{c}\right)} & -\frac{1}{C\left(R+R_{c}\right)}
\end{array}\right]} \\
& {\left[\begin{array}{c}
V_{p v} \\
i \\
V_{D C}
\end{array}\right]+\left[\begin{array}{c}
\frac{R_{S h}}{C_{e}\left(R_{S h}+R_{S}\right)} \\
0 \\
0
\end{array}\right] u_{2}+\left[\begin{array}{c}
\frac{R_{c} R-R_{M} R_{c}-R_{M} R}{L\left(R_{c}+R\right)} \mathrm{i}+\frac{R}{L\left(R_{c}+R\right)} \\
-\frac{R}{C\left(R+R_{C}\right)} \mathrm{i}
\end{array} V_{\mathrm{DC}}+\frac{1}{L} V_{\gamma}\right]} \\
& u_{1}+\left[\begin{array}{c}
0 \\
-\frac{1}{L} \\
0
\end{array}\right] V_{\gamma} \\
& \text { with } u(t)=\left(\begin{array}{l}
u_{d} \\
i_{L d}
\end{array}\right)=\left(\begin{array}{l}
u_{1} \\
u_{2}
\end{array}\right) \\
& \text { and } I_{L d}=I_{L}-I_{d} \\
& \text { with } I_{d}=I_{0}\left[\exp \left(\frac{V_{d}}{V_{T}}\right)-1\right]+\frac{V_{d}}{R_{s h}}+\frac{V_{d}}{R_{s h}} S_{\text {ref }} \\
& \text { and } I_{L}=\frac{s}{s_{\text {ref }}}\left[I_{\text {Lref }}+\alpha_{i s c}\left(T_{\text {cell }, k}-T_{\text {ref }, k}\right)\right] \\
& V_{T}=\frac{K T}{q} n_{I} N_{\text {cell }} N_{\text {ser }} \\
& V_{d}=V_{p v}+R_{s} I_{p v}
\end{aligned}
$$

Equations (4), (5), and (8) are extracted from the equivalent electric circuit of Figure1 by using Kirchhoff's laws.

\section{B. Oriented Controller}

Model-based approach was established to improve the performance of the oriented controller. The plant of the system is represented in a boost converter that functions as an interface between the PV array and load. The purpose behind controloriented techniques is to achieve impedance matching between the output of PV panels and load conditions. To achieve such matching, the differential equations extracted through the state space averaging method were linearized around an operating point. In the steady state, we calculated the equilibrium point using Taylor series. We thus used the closed loop of the system matrix that we obtained through the model-based approach to derive poles, after which we employed the Ackerman formula and the pole placement method to calculate the feedback gain matrix. Improving the efficiency of a controller designed for
PV systems necessitates an accurate modeling plant as this enhances the choice of control technique to be used. The model-based approach provides an actual estimation of the dynamic behavior of a system and presents a simple means of verifying the occurrence of a fault by matching the difference between the measured and calculated parameters to reference values [7]. Finally, it can advance the fault detection and diagnosis of solar systems given that most methods require the plant of a system.

\section{BUCK CONVERTER}

This section describes the buck converter concept, its operation and a definition of the model-based approach adopted in this work.

\section{A. Concept and Operation}

A buck converter is a switching device that enables the simultaneous decrease of the output voltage and increase of the output current, respectively, while maintaining the level of power received in the input. Figure 2 shows the topology of a buck converter connected to a PV array. In [8], an exact description of the topology and basic operation of a buck converter is presented. The authors demonstrated the use of the following equations:

$$
\begin{aligned}
& V_{D C}=\alpha V_{p v} \\
& I_{D C}=\frac{1}{\alpha} I_{p v}
\end{aligned}
$$

By using (9) and (10) we obtain:

$\frac{V_{D C}}{I_{D C}}=\alpha^{2} \frac{V_{p v}}{I_{p v}}$

We know that:

$R_{p v}=\frac{V_{p v}}{I_{p v}} \quad$ and $R_{D C}=\frac{V_{D C}}{I_{D C}}$

Putting (12) in (11) results in:

$$
\begin{aligned}
& R_{D C}=\alpha^{2} R_{p v} \\
& \alpha=\sqrt{\frac{R_{D C}}{R_{p v}}}
\end{aligned}
$$

For a buck converter to work effectively, according to (14), $R_{D C}$ must be always inferior to $R_{p v}$ because $\alpha$ is always inferior to 1 .

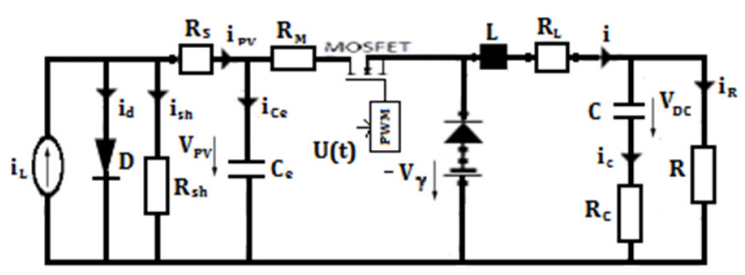

Fig. 2. Equivalent electrical circuit of the system with a buck converter

\section{B. Model-based Approach for a Buck Converter}

The first step in building the model-based approach is to extract the differential equations for ON and OFF operations in the continuous conduction mode of the buck converter. Figure 
3 illustrates the on mode of the buck converter connected to a PV array.

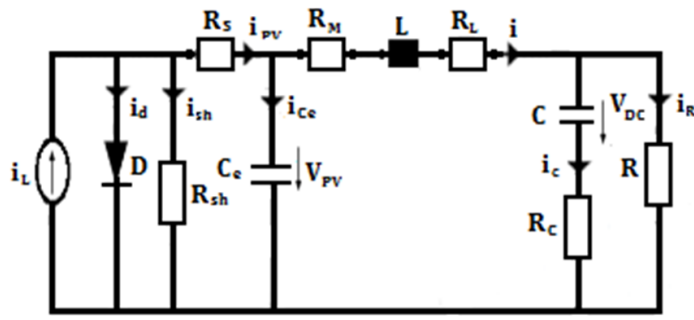

Fig. 3. Electrical circuit of the ON mode of the buck converter

$$
\begin{aligned}
& \frac{d V_{P V}}{d t}=-\frac{1}{C_{e}\left(R_{S h}+R_{S}\right)} V_{P V}-\frac{1}{C_{e}} \mathrm{i}+\frac{R_{S h}}{C_{e}\left(R_{S h}+R_{S}\right)} i_{L d} \\
& \frac{d i}{d t}=\frac{1}{L} V_{P V}-\left(\frac{R R_{C}+R_{L} R_{C}+R R_{L}}{L\left(R_{C}+R\right)}\right) i-\frac{R}{L\left(R_{C}+R\right)} V_{D C} \\
& \frac{d V_{D C}}{d t}=\frac{R}{C\left(R+R_{C}\right)} i-\frac{1}{C\left(R+R_{C}\right)} V_{D C}
\end{aligned}
$$

Equations (15)-(17) represent the dynamic state-space modeling of the ON stage illustrated in Figure 3. Equations (21)-(23) exhibit the derivative states of the OFF mode shown in Figure 4. We note that the derivative of the state variable $V_{D C}$ is equal in the ON and OFF mode because the dynamics of the system doesn't change.

$$
\begin{aligned}
& \frac{d V_{P V}}{d t}=-\frac{1}{C_{e}\left(R_{S h}+R_{S}\right)} V_{P V}+\frac{R_{S h}}{C_{e}\left(R_{S h}+R_{S}\right)} i_{L d} \\
& \frac{d i}{d t}=-\left(\frac{R R_{C}+R_{L} R_{C}+R R_{L}}{L\left(R_{C}+R\right)}\right) i-\frac{R}{L\left(R_{C}+R\right)} V_{D C}-\frac{1}{L} V_{\gamma} \\
& \frac{d V_{D C}}{d t}=\frac{R}{C\left(R+R_{C}\right)} i-\frac{1}{C\left(R+R_{C}\right)} V_{D C}
\end{aligned}
$$

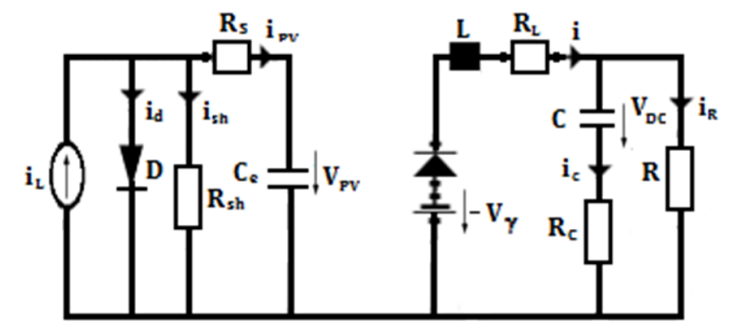

Fig. 4. Electrical circuit of the OFF mode of the buck converter

If we go back to Figure 1 describing the electrical circuit of the boost converter, we can tell that $i_{p v}$ is equal to $i$ regardless of the ON or OFF condition of the switcher because the capacitance input $C_{e}$ is very small, so (8) can be written as:

$$
V_{d}=V_{p v}+R_{s} I
$$

where $i$ represents the state variable through the inductance.

For the buck converter defined in Figure 3 we notice that $i_{p v}$ is different from $i$ depending on the switcher's mode, where:

$$
i_{p v}=\frac{R_{s h}}{\left(R_{s h}+R_{s}\right)} i_{L d}-\frac{1}{\left(R_{s h}+R_{s}\right)} V_{p v}
$$

In this case, (8) can be written as:

$$
\mathrm{V}_{\mathrm{d}}=\frac{R_{S h}}{\left(R_{S h}+R_{S}\right)} \mathrm{V}_{\mathrm{pv}}+\frac{R_{S h} \mathrm{R}_{\mathrm{s}}}{\left(R_{S h}+R_{S}\right)} i_{L d}
$$

$i_{L d}$ is expressed in (4), $I_{L}$ is the light generated by the sun and $I_{d}$ is the diode current. The differential equations of the $\mathrm{ON}$ and OFF modes can be summarized according to (24). The state space averaging system, which combines both time switches, is presented in (27) by using (25):

$$
\begin{aligned}
& \dot{x}(t)=A x(t)+B(x) u_{1}(t)+B^{\prime} u_{2}(\mathrm{t}) \\
& \dot{x}(t)=\dot{x}_{\text {on }} u_{1}+\dot{x}_{\text {off }}\left(1-u_{1}\right)
\end{aligned}
$$

where the input $u_{\mathrm{d}}=u_{1}$ is related to the switch mode, and $i_{L d}$ is the incontrollable input representing the sun light.

$$
S=\left\{\begin{array}{cl}
O N ; & \text { MOSFET ON } \\
O F F ; & \text { MOSFET OFF }
\end{array}\right.
$$$$
\text { with } S_{O N}(u)=u_{1}, S_{O F F}(u)=1-u_{1}, u_{1} \in[0,1] \text {, }
$$

$$
\underline{x}=\left(\begin{array}{c}
V_{P V} \\
i \\
V_{D C}
\end{array}\right)=\left(\begin{array}{l}
x_{1} \\
x_{2} \\
x_{3}
\end{array}\right)
$$

The system matrix of the buck converter connected to the PV array:

$$
\begin{gathered}
{\left[\begin{array}{c}
\frac{d V_{P V}}{d t} \\
\frac{d i}{d t} \\
\frac{d V_{D C}}{d t}
\end{array}\right]=\left[\begin{array}{ccc}
-\frac{1}{C_{e}\left(R_{S h}+R_{S}\right)} & 0 & 0 \\
0 & -\left(\frac{R R_{c}+R_{L} R_{c}+R R_{L}}{L\left(R_{c}+R\right)}\right) & -\frac{R}{L\left(R_{c}+R\right)} \\
0 & \frac{R}{C\left(R+R_{c}\right)} & -\frac{1}{C\left(R+R_{c}\right)}
\end{array}\right]} \\
{\left[\begin{array}{c}
V_{p v} \\
i \\
V_{D C}
\end{array}\right]+\left[\begin{array}{c}
\frac{R_{S h}}{C_{e}\left(R_{S h}+R_{S}\right)} \\
0 \\
0
\end{array}\right] i_{\mathrm{LD}}+\left[\begin{array}{c}
-\frac{1}{C_{e}} \mathrm{i} \\
\frac{1}{L} V_{p v}+\frac{1}{L} V_{\gamma} \\
0
\end{array}\right] u_{\mathrm{d}}+\left[\begin{array}{c}
0 \\
-\frac{1}{L} \\
0
\end{array}\right] V_{\gamma}}
\end{gathered}
$$

The validation of the state space model is confirmed by Figure 5, which shows the similarity between the mathematical implementation of the equivalent circuit of the system and the use of Simscape devices on Simulink/Matlab.

\section{BUCK-BOOST CONVERTER}

\section{A. Concept and Operation}

There are different buck-boost converter topologies [8, 9], each appropriate for a particular application. The buck-boost gives a negative output voltage when used without isolation. The property of this converter is that, it can be a step up or step down of the input voltage, according to the following notation:

$$
\begin{aligned}
& \alpha>0.5, \text { its a boost converter } \\
& \alpha<0.5, \text { its a buck converter } \\
& \alpha=0.5, \text { its unity gain }
\end{aligned}
$$

Equations (28)-(30), express the relation between the input and output of the converter depending on the duty cycle:

$$
\begin{aligned}
& V_{D C}=\frac{\alpha}{(1-\alpha)} V_{P V} \\
& I_{D C}=\frac{(1-\alpha)}{\alpha} I_{P V}
\end{aligned}
$$




$$
\frac{\mathrm{V}_{\mathrm{DC}}}{\mathrm{I}_{\mathrm{DC}}}=\left(\frac{\alpha}{1-\alpha}\right)^{2} \frac{V_{P V}}{I_{P V}}
$$

Applying (12) and considering (30), the expression of the duty cycle can be written as:

$$
\frac{\alpha}{(1-\alpha)}=\sqrt{\frac{R_{D C}}{R_{p v}}}
$$

According to (31) and contrary to the boost and buck converter, the system will function properly in all scenarios, either when $R_{D C}$ is inferior, superior or equal to $R_{P V}$. That's why the equivalent electrical circuit of the buck-boost converter presented in Figure 6 is the optimal solution to extract the maximum power from renewable energy systems (e.g. sun systems).
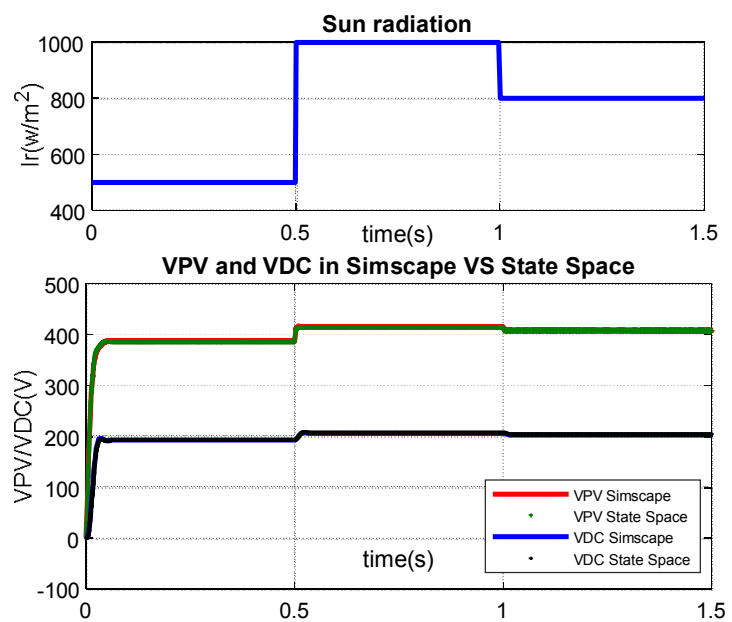

iPV and iDC in Simscape VS State Space

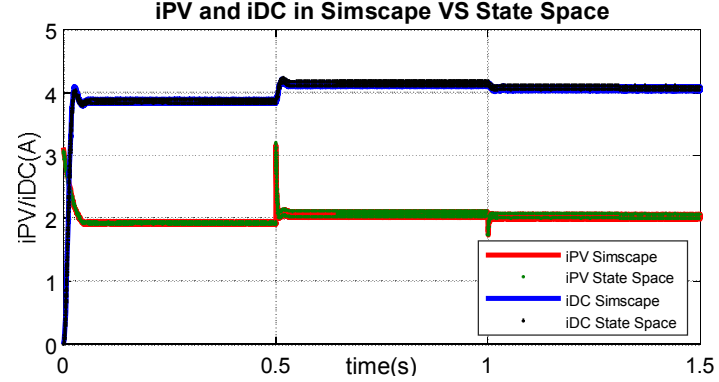

Fig. 5. Validation of the model Simscape Vs State Space

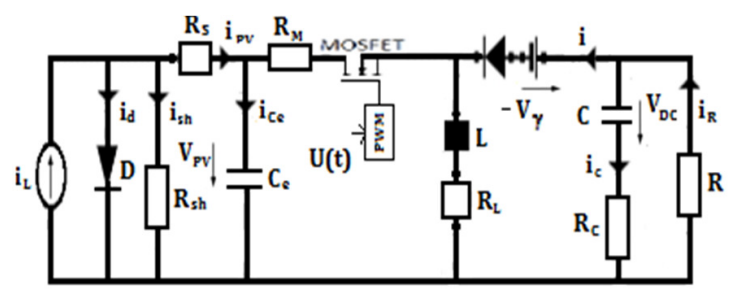

Fig. 6. Electrical circuit of the system with a buck-boost converter

\section{B. Model-based Approach for a Buck-Boost Converter}

The state space equations when the switcher is in the ON mode are written in (32)-(34), according to Figure 7.

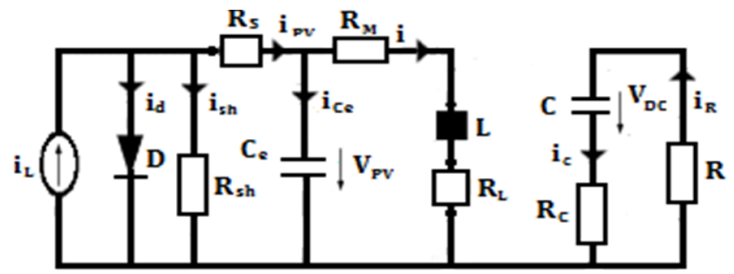

Fig. 7. Electrical circuit of the ON mode of the buck-boost converter

$$
\begin{aligned}
& \frac{d V_{P V}}{d t}=-\frac{1}{C_{e}\left(R_{S h}+R_{S}\right)} V_{P V}-\frac{1}{C_{e}} \mathrm{i}+\frac{R_{S h}}{C_{e}\left(R_{S h}+R_{S}\right)} i_{L d} \\
& \frac{d i}{d t}=\frac{1}{L} V_{P V}-\frac{\left(R_{M}+R_{L}\right)}{L} i \\
& \frac{d V_{D C}}{d t}=-\frac{1}{C\left(R+R_{C}\right)} V_{D C}
\end{aligned}
$$

The input $i_{L d}$ is defined in (4), and the same logic is applied as the buck converter regarding $V_{d}$ defined in (23) for both switching times. The state equations for the OFF state are given by (35)-(37), according to Figure 8.

$$
\begin{aligned}
& \frac{d V_{P V}}{d t}=-\frac{1}{C_{e}\left(R_{S h}+R_{S}\right)} V_{P V}+\frac{R_{S h}}{C_{e}\left(R_{S h}+R_{S}\right)} i_{L d} \\
& \frac{d i}{d t}=-\left(\frac{R R_{C}+\mathrm{R}_{\mathrm{C}}{ }^{2}+R R_{L}}{L R}\right) i-\frac{R_{C}-R}{L R} V_{D C}-\frac{1}{L} V_{\gamma} \\
& \frac{d V_{D C}}{d t}=-\frac{R}{C\left(R+R_{C}\right)} i-\frac{1}{C\left(R+R_{C}\right)} V_{D C}
\end{aligned}
$$

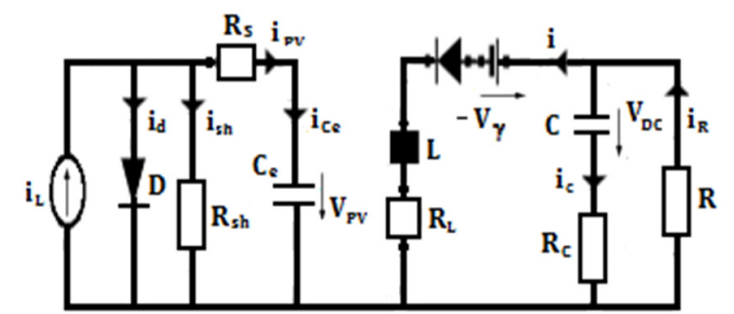

Fig. 8. Electrical circuit of the OFF mode of the buck-boost converter

The state space averaging model for the buck-boost converter results in (38). It's a set of state equations equivalent to the ON and OFF switching states. We note that the matrix of the PV generator connected to the buck-boost was written according to (25) defined in the section of the buck converter.

$$
\begin{aligned}
& {\left[\begin{array}{c}
\frac{d V_{P V}}{d t} \\
\frac{d i}{d t} \\
\frac{d V_{D C}}{d t}
\end{array}\right]=\left[\begin{array}{ccc}
- & \frac{1}{C_{e}\left(R_{S h}+\boldsymbol{R}_{s}\right)} & 0 \\
0 & -\left(\frac{R R_{c}+\mathrm{R}_{\mathrm{c}}{ }^{2}+R R_{L}}{L \mathrm{R}}\right) & -\frac{R_{c}-R}{L \mathrm{R}} \\
0 & -\frac{\boldsymbol{R}}{\boldsymbol{C}\left(\boldsymbol{R}+\boldsymbol{R}_{c}\right)} & -\frac{\mathbf{1}}{\boldsymbol{C}\left(\boldsymbol{R}+\boldsymbol{R}_{c}\right)}
\end{array}\right]\left[\begin{array}{c}
V_{p v} \\
i \\
V_{D C}
\end{array}\right]} \\
& +\left[\begin{array}{c}
\frac{R_{S h}}{C_{e}\left(R_{S h}+R_{S}\right)} \\
0 \\
0
\end{array}\right] i_{\mathrm{LD}}+\left[\begin{array}{c}
\frac{1}{C_{e}} V_{p v}+\frac{R R_{c}+\mathrm{R}_{\mathrm{c}}{ }^{2}-R R_{M}}{L \mathrm{R}} \mathrm{i}+\frac{R_{c}-R}{L \mathrm{R}} V_{D C}+\frac{1}{L} V_{\gamma} \\
\frac{R}{C\left(R+R_{c}\right)} \mathrm{i}
\end{array}\right] \\
& u_{\mathrm{d}}+\left[\begin{array}{c}
0 \\
-\frac{1}{L} \\
0
\end{array}\right] V_{\gamma}
\end{aligned}
$$




\section{Simulation and Discussion}

The Simscape notation means that the circuit was designed by using devices available in the Simscape library and the State Space means that the circuit was designed by mathematic modeling using the State Space method (which consists of equations implemented in Simulink and they are not the predefined devices available in Simscape). The comparison between the simulation of the circuit designed by Simscape devices and the one designed by the analytical solution confirms that the mathematic solution is as accurate as the circuit built by detailed devices given by Simscape. For simulation, the powergui used in the Simulink model is set as continuous mode with variable step size of maximum $0.0001 \mathrm{~s}$, and ode23tb (stiff/TR-BDF2) as a solver. In Figure 9, we can see that when $\alpha=0.5$ the input voltage and current of the buckboost converter is equal to the inverse of the output with $i_{P V}$ defined in (22) and $i_{D C}$ is as follows:

$$
i_{D C}=\frac{V_{D C}}{R}
$$

The model is validated by the comparison between the Simscape and State Space model for the three possibilities of the controllable input $\alpha$ presented in Figures 9-11.
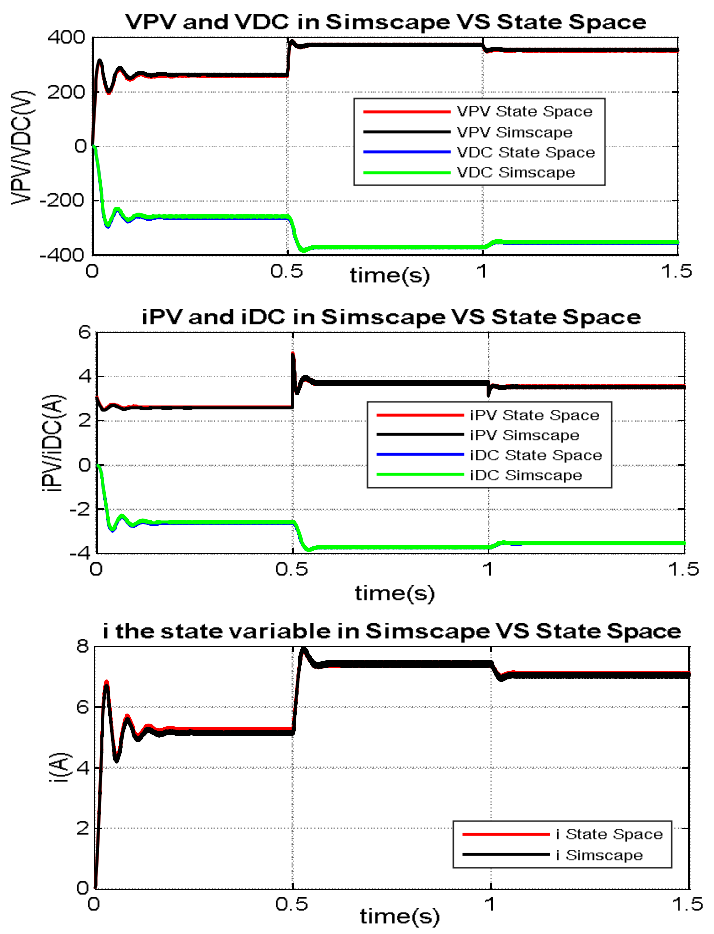

Fig. 9. Validation of the model for $\alpha=0.5$

Figure 10 shows the boost converter mode (e.g. the output voltage is higher than the input) but the polarities are inversed and Figure 11 the buck converter mode (e.g. the output current is higher than the input). Observing the equivalent electrical circuit of the ON and OFF mode of each converter presented, can lead us to understand the flux of the current which represents the state variable $i$. It's important to analyze the dynamic behavior of the states, so an accurate model can be built and used in a proper way to design the oriented controller. We have noticed that for the boost converter the state variable $i$ is equal to the PV current $i_{P V}$, for the buck converter the state variable $i$ is equal to the output DC current $i_{D C}$, and for the buck-boost converter the state variable $i$ is different from $i_{P V}$ and $i_{D C}$ as shown in Figure 9. This can influence the result given by the controller if we use the mathematical modeling without differentiating between the state variables and the inputs/outputs of the system.
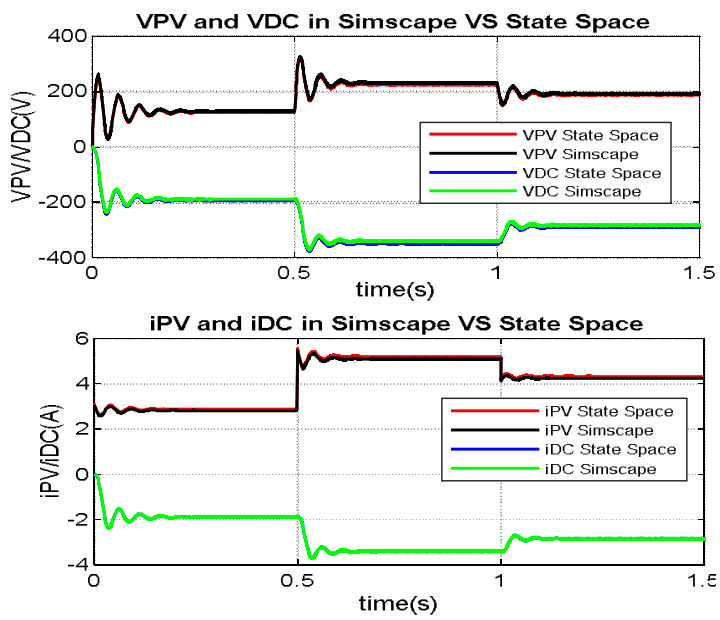

Fig. 10. Validation of the model for $\alpha=0.6$ (boost mode)

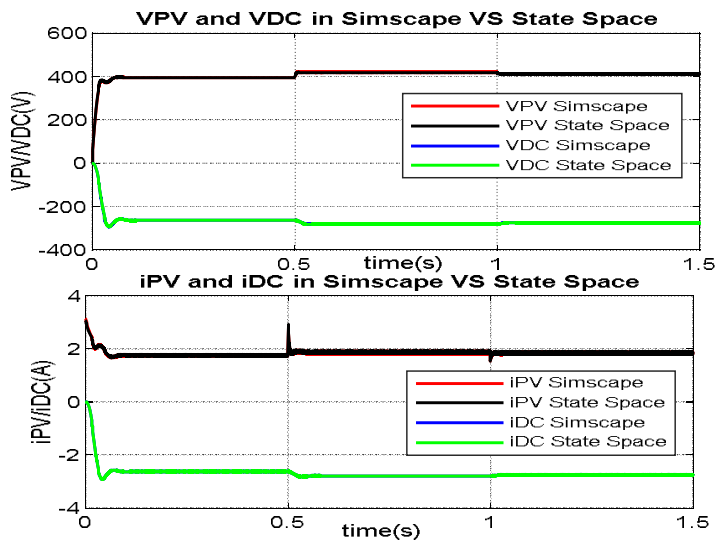

Fig. 11. Validation of the model for $\alpha=0.4$ (buck mode)

\section{CONCLUSION AND OUTLOOK}

Based on the simulation results shown in this paper, the model-based approach is validated. It also demonstrates the accuracy of the system matrix extracted from the differential equations depending on the equivalent electrical circuit of each converter connected to the PV array. The model-based approach is a mathematical modeling of the system based on the state space method destined for photovoltaic generators. It allows defining and understanding the comportment of the state variables, as well as the input and output signals. It consists of predefined models of boost, buck and buck boost converter and can benefit from further work that involves power conversion sun systems. In this paper an analysis of the buck and buck- 
boost converter was conducted. The state space model of the buck-boost converter will be used in our future research: It will be adopted to build an oriented controller design.

\section{NOMENCLATURE}

$K: \quad$ Boltzmann's constant $\left(1.3806 \times 10^{-23} \mathrm{~J}^{\left.-\mathrm{K}^{-1}\right)}\right.$

$q$ : $\quad$ Electron charge $\left(1.6022 \times 10^{-19} \mathrm{C}\right)$

$V_{d}: \quad$ Diode Voltage (V)

$I_{d}: \quad$ Diode current (A)

$I_{L}$ : $\quad$ Generated light produced by the sun

$I_{\text {Lref }}: \quad$ Reference of the generated light (1.2653A)

$T: \quad$ Temperature $(\mathrm{K})$

$u_{d} / \alpha: \quad$ Duty cycle

$R_{S}: \quad$ Series resistance $(16.135 \Omega)$

$R_{s h}: \quad$ Shunt resistance $(254.8279 \Omega)$

$I_{0}$ : $\quad$ Diode saturation current $\left(2.2521 \times 10^{-12} \mathrm{~A}\right)$

$\alpha_{i s c}: \quad$ Temperature coefficient $\left(1.904 \times 10^{-3}\right)$

$n_{I}: \quad$ Diode ideality factor $(0.98117)$

$N_{\text {cell }}: \quad$ Number of cells in series

$\mathrm{S}: \quad$ Irradiation of the sun

$S_{\text {ref }}: \quad$ Reference of the sun irradiation (0.001)

$N_{\text {ser }}: \quad$ Number of modules connected in series

$N_{\text {par }}$ : Number of modules connected in parallel

$T_{\text {ref-K }}: \quad 298.15 \mathrm{~K}$

\section{REFERENCES}

[1] http://prima-med.org/

[2] A. M. Garcia, J. Gallagher, A. McNabola, E. C. Poyato, P. M. Barrios, J. A. R. Diaz, "Comparing the environmental and economic impacts of onor off-grid solar photovoltaics with traditional energy sources for rural irrigation systems", Renewable Energy, Vol. 140, pp. 895-904, 2019

[3] S. Meunier, M. Heinrich, L. Queval, J. A. Cherni, L. Vido, A. Darga, P. Dessante, B. Multon, P. K. Kitanidis, C. Marchand, "A validated model of a photovoltaic water pumping system for off-grid rural communities", Applied Energy, Vol. 241, pp. 580-591, 2019

[4] N. H. Baharudin, T. M. N. T. Mansur, F. A. Hamid, R. Ali, M. I. Misrun, "Topologies of dc-dc converter in solar pv applications", Indonesian Journal of Electrical Engineering and Computer Science, Vol. 8, No. 2, pp. 368-374, 2017

[5] Z. R. Labidi, H. Schult, A. Mami, "A systematic controller design for a photovoltaic generator with boost converter using integral state feedback control", Engineering, Technology and Applied Science Research, Vol. 9, No. 2, pp. 4030-4036, 2019

[6] R. H. G. Tan, L. Y. H. Hoo, "DC-DC Converter Modeling and Simulation Using State Space Approach", IEEE Conference on Energy Conversion, Johor Bahru, Malaysia, October 19-20, 2015

[7] J. A. Tsanakas, L. Ha, C. Buerhop, "Faults and infrared thermographic diagnosis in operating c-Si photovoltaic modules: A review of research and future challenges", Renewable and Sustainable Energy Reviews, Vol. 62, pp. 695-709, 2016

[8] I. Batarseh, A. Harb, Power Electronics: Circuit Analysis and Design, Springer, 2018

[9] Y. Chen, B. Zhang, Equivalent-Small-Parameter Analysis of DC/DC Switched-Mode Converter, Springer 2019 